\title{
Macroplastic research in an era of microplastic
}

\author{
Tim van Emmerik
}

Plastic pollution and its negative impacts are getting a more prominent spot on the international agenda every year. Governments, non-governmental organizations, industry, and international organizations are launching new initiatives to reduce plastic waste in marine, riverine and terrestrial environments. Examples include Indonesia's ambition to reduce marine plastic debris by $70 \%$, the European Union's Single-Use Plastics Ban, and a plastic producer-led alliance to end plastic waste [1-3]. On the local scale, cities across the world have committed to reducing plastic leakage into the environment through best practices in research, waste infrastructure, and monitoring (e.g. Worldwide Fund for Nature's Plastic Smart Cities and the United Nations Economic and Social Commission for Asia and the Pacific's Closing the Loop projects). For such ambitions to succeed, a thorough understanding and accurate data about plastic sources, emissions, fate, effects, and risks are crucial. As the scientific plastic pollution community we have an important task to contribute to this.

Plastic pollution comes in many different shapes, colors, polymers, and - perhaps most important - sizes. Plastic science seems divided into subfields based on size classes (nano, micro, macro) of which the boundaries are mainly determined by methodological limits. In recent years there has been increasing attention for macroplastic $(>0.5 \mathrm{~cm})$ research. Macroplastics are estimated to be one of the main sources of marine plastic pollution and secondary microplastics, and have direct negative effects on ecosystem health and human livelihood [4]. The growing interest in macroplastics from scientists, governments and environmental organizations has accelerated the development of methods to quantify sources, sinks, and pathways. Until recently, most macroplastic field observations had to be done using fairly simple

Correspondence: tim.vanemmerik@wur.nl

Hydrology and Quantitative Water Management Group, Wageningen University, Wageningen, The Netherlands methods, such as net sampling or visual counting. This is in stark contrast with current possibilities for macroplastic monitoring in aquatic ecosystems. Large-scale monitoring efforts use the power of citizen science, facilitated by easy-to-use mobile applications such as CrowdWater or Litterati. Drones now allow for measuring plastic litter at complex or unsafe areas, such as river mouths and mangrove forests. Automated monitoring can be done using a combination of (multispectral) camera imagers and artificial intelligence. Even in the world's most remote places plastic debris can now be detected using remote sensing imagery [5]. Now macroplastic research is not constrained anymore by methodological challenges, we are entering a phase in which we can focus on answering fundamental questions.

With the first long-term and large-scale macroplastic data being collected on land, in rivers and in the oceans, new scientific questions are emerging. It has been hypothesized that hydrometeorological variables such as wind, surface runoff, and river flow dynamics are the main drivers of macroplastic transport. Recent observations reveal that reality may be substantially more complex, and more importantly, vary greatly around the world. In some river systems (e.g. Seine, Rhine, Meuse) macroplastics are found to accumulate in tidal zones, rather than flow into the ocean. In other rivers (Saigon, Mekong) the spatiotemporal variation in macroplastics is apparently determined by the seasonal dynamics of water hyacinths, as this invasive species seem to be very effective in capturing plastic debris. These examples emphasize the importance of local observation-based studies, to improve our fundamental understanding of plastic transport dynamics. Additional effort is also required to investigate the effect of natural hazards on plastic mobilization, transport and emissions. Sporadic assessments have shown that tsunamis or floods are important drivers of plastic transport [6], but fundamental studies are still lacking. Finally, a crucial challenge 
remains quantifying macroplastics below the surface and in sediment. New cost-effective methods are emerging (e.g. using echo sounding), but have not been applied on large scale. There are still many questions to answer, but given the rapid process of the science we have plenty of reasons to be optimistic about the upcoming advances in the near future.

Macroplastics play a fundamental role in the global plastic pollution challenge. New monitoring methods offer unprecedented opportunities for further upscaling of data collection in time and space. With increased data availability, the plastic community can focus on improving source, fate, and effect assessments, and strengthen the link between macro-, micro- and nanoplastic research to make it whole. We should actively stimulate the acceleration of plastic research by data collection across size ranges, close collaboration with stakeholders, and targeted projects to answer the open fundamental science questions. Only then we can fully fulfil our task, providing the science necessary to achieve the global ambitions to reduce plastic emissions into the environment.

\section{Author's contributions}

The author read and approved the final manuscript.

\section{Declarations}

\section{Competing interests}

The authors declare that they have no competing interests.

Published online: 29 March 2021

\section{References}

1. Elliott T, Gillie H, Thomson A. European Union's plastic strategy and an impact assessment of the proposed directive on tackling single-use plastics items. In: Plastic waste and recycling: Cambridge, Massachusetts: Academic; 2020. p. 601-33.

2. Nurhati IS, Cordova MR. Marine plastic debris in Indonesia: baseline estimates (2010-2019) and monitoring strategy (2021-2025). Mar Res Indones. 2020:45(2):1-6.

3. Peake L. Plastic waste in the United Kingdom. In: Plastic waste and recycling: Cambridge, Massachusetts: Academic; 2020. p. 585-600.

4. van Emmerik T, Schwarz A. Plastic debris in rivers. Wiley Interdiscip Rev Water. 2020;7(1):e1398.

5. Biermann L, Clewley D, Martinez-Vicente V, Topouzelis K. Finding plastic patches in coastal waters using optical satellite data. Sci Rep. 2020;10(1):110.

6. Roebroek $C T$, Harrigan S, van Emmerik TH, Baugh C, Eilander D, Prudhomme C, et al. Plastic in global rivers: are floods making it worse? Environ Res Lett. 2021;16(2):025003. https://doi.org/10.1088/1748-9326/abd5df.

\section{Publisher's Note}

Springer Nature remains neutral with regard to jurisdictional claims in published maps and institutional affiliations.

\section{Submit your manuscript to a SpringerOpen ${ }^{\circ}$ journal and benefit from:}

- Convenient online submission

- Rigorous peer review

- Open access: articles freely available online

High visibility within the field

- Retaining the copyright to your article

Submit your next manuscript at $\boldsymbol{\nabla}$ springeropen.com 